\title{
Editorial
}

\section{Stem cells and medical tourism}

An Internet browser search for "stem cell treatment" will bring up an amazing assortment of claims and professionally prepared overt advertisements for therapy of many chronic diseases and disabilities [1, 2]. Among others, the most common include cardiovascular disorders including acute myocardial infarction, stroke, spinal cord injuries, Parkinsonism, multiple sclerosis, Alzheimer disease, cerebral palsy, erectile dysfunction, diabetes, amyotrophic lateral sclerosis, osteoarthritis, burns, facioscapulohumeral muscular dystrophy (LandouzyDejerine syndrome), liver disease, kidney disease, and psychiatric illnesses, including autism. Not only are some so-called "stem cell clinics" promoting treatment of disease, but some are targeting otherwise healthy patients for cosmesis, including hair regrowth, breast augmentation, cosmetic anti-aging treatment, and nonsurgical face lifts, or health enhancement including "enhanced sexual function", "regain of youthful vigor", "increased feelings of energy", and "increased mental capacity". Currently, only the treatment of well-defined hematological diseases using bone marrow transplantation is widely used in clinical practice [3-6]. This clinical use of stem cells has been approved by responsible government authorities such as the U.S. Food and Drug Administration (U.S. FDA) using approved protocols that are subject to scrutiny and supervision. Other stem cell therapies have been approved by the U.S. FDA or are undergoing registered clinical trials, but their use has been much less widespread $[7,8]$.

Research in utilizing stem cells for treatment or replacement, also known as regenerative or reparative medicine, is an exciting field. It is. However, it is also still in its infancy, but rapidly evolving and showing great promise. Stem cells can be obtained from blood, bone marrow, tissues (e.g. adipose, skin, and placenta), umbilical cords, fetuses, or embryos, and then cultured. These cells offer much promise for future therapies $[3,9,10]$. Most, if not all, stem cells need to be chemically or physically manipulated or transformed to make them able to perform complex new functions. An undifferentiated stem cell needs to be transformed

Correspondence to: Editorial Office of Asian Biomedicine, Faculty of Medicine, Chulalongkorn University, Bangkok 10330, Thailand. E-mail: chulamed@md.chula.ac.th into a functional cell, such as a nerve, muscle, fat, bone, or blood cell before it is of any use in therapy [11]. Completely new technologies, based on innovative and complex molecular and genetic experimentation, must be developed before the virtual miracle expected in stem cell treatment can be realized. To understand the complexity of what we expect from a stem cell, a colony of such cells, infused intravenously or injected directly into brain or spinal cord, must then find their way to the site where these cells are needed. They must be able to defend themselves or hide from attacks of the patient's immune system. If infused intravenously, they must not become stuck in the liver or lung on their way to the injured target site. There, they must then be transformed start to reproduce and be able to function.

Up to dozens of commercial clinics worldwide are advertising some stem cell treatments without any scientifically acceptable substantiated evidence that the treatments are safe and effective. Such clinics are usually located in countries that have lax laws dealing with such practices, or lax enforcement of existing laws. These countries may not provide for supervision or licensing of such activities allowing the laws to be evaded, corrupted, or skirted around by what is now a very lucrative and growing industry $[1,12,13]$. Documented success and failure data from some such clinics cannot be found in the scientific literature. However, testimonials abound in the media and material offered by such clinics $[1,14]$. Testimonials can be elicited from patients, but these alone are not sufficient evidence of effectiveness or safety. The evidence that "some patients seem to have benefited from the treatment" is not sufficient. The evidence must be subject to the stricter rules of scientific enquiry and must be verified, and this can only be done by long-term peer reviewed and unbiased follow-ups. Many of the diseases treated by this group of very profitable providers have slowly progressive natural histories, remissions, and exacerbations. To determine efficacy and safety requires studies of large numbers of patients for long periods of time [15]. Patients who seek "last chance" experimental treatments for terminal or otherwise incurable conditions, after having apparently exhausted other avenues, are especially vulnerable to medical charlatans who openly prey on the vulnerable with 
impunity, and these patients may have little or no legal recourse. Reputable international research centers that carry out legitimate trials of promising new technologies are often open for patients to volunteer for clinical trials of experimental treatments. There are several places to obtain more information regarding legitimate clinical trials [16, 17].

In Asia, there are commercial stem cell treatment centers in many countries including Thailand, Malaysia, India, The Philippines, China, and Hong Kong. Efforts have been made by several medical authorities and governments to regulate unethical, unproven, and sometimes criminal conduct by so-called "Stem Cell Centers" [12]. However, even in the tightly regulated United States of America, there are unscrupulous doctors and others who attract desperate patients and refer them to clinics abroad for profit. The U.S. FDA has warned consumers about stem cell claims [18]. Asian Biomedicine restricts itself to publish only work that is substantiated scientifically, approved by an ethics committee, peer reviewed, and acceptable on moral and ethical stands [19]. We and other legitimate organizations strongly discourage stem cell therapy tourism at this still early time $[14,15,20]$. Patients who do contemplate undergoing stem cell treatment abroad, should first carefully educate themselves concerning current knowledge and consult their personal physicians and medical institutions back home. Medical tourism now and in the future may include "proven stem cell therapies". Such treatments, e.g. hematopoietic stem cell treatment for certain hematological diseases such as leukemia, may not be available or may be prohibitively expensive for patients in their own countries. In the future, other proven treatments, perhaps involving the use of embryonic stem cells, may be banned in certain countries for political or religious reasons. Patients should remain free to travel to clinics offering proven stem cell-based therapies. However, they must be able to distinguish between acceptable medical travel for proven therapies and problematic stem cell tourism. In this issue of Asian Biomedicine, Malaysian religious perspectives regarding the ethics of embryonic stem cell research are reviewed by Sivaraman and Noor [21]. Stem cells offer exciting promise for future therapies, but significant technical hurdles remain that will only be overcome through extensive and intensive research. Two articles in this issue of Asian Biomedicine address stem cell technology. The article by Ai et al. from Iran [22] reports original research and the other by Hua et al. from China [23] reviews therapeutic cloning in the light of induced pluripotent stem cell technology.

\section{References}

1. Lau D, Ogbogu U, Taylor B, Stafinski T, Menon D, Caulfield T. Stem cell clinics online: the direct-toconsumer portrayal of stem cell medicine. Cell Stem Cell. 2008; 3:591-4.

2. Stem cell clinics list. [cited 2014 February 13], Available from: http://www.stemcellsfreak.com/p/stem-cellclinics-list.html

3. Andersson ER, Lendahl U. Regenerative medicine: a 2009 overview. J Intern Med. 2009; 266:303-10.

4. Teo AK, Vallier L. Emerging use of stem cells in regenerative medicine. Biochem J. 2010; 428:11-23.

5. de la Morena MT, Gatti RA. A history of bone marrow transplantation. Immunol Allergy Clin North Am. 2010; 30:1-15.

6. Gratwohl A, Baldomero H, Aljurf M, Pasquini MC, Bouzas LF, Yoshimi A, et al., for the Worldwide Network of Blood and Marrow Transplantation. Hematopoietic stem cell transplantation: a global perspective. JAMA. 2010; 303:1617-24

7. Hentze H, Graichen R, Colman A. Cell therapy and the safety of embryonic stem cell-derived grafts. Trends Biotechnol. 2007; 25:24-32.

8. FDA Regulation of human cells, tissues, and cellular and tissue-based products (HCT/P's) product list [05/12/2009] U.S. Food and Drug Administration [cited 2014 February 13], Available from: http://www.fda. gov/BiologicsBloodVaccines/TissueTissueProducts/ RegulationofTissues/ucm150485.htm

9. Daley GQ. Stem cells: roadmap to the clinic. J Clin Invest. 2010; 120:8-10.

10. Kolios G, Moodley Y. Introduction to stem cells and regenerative medicine. Respiration. 2013; 85:3-10.

11. Stem cell basics: introduction In: Stem Cell Information. Bethesda, MD: National Institutes of Health, U.S. Department of Health and Human Services. April 28, 2002 [cited 2014 February 13], Available from: http:// stemcells.nih.gov/info/basics/pages/basics1.aspx

12. Sipp D. The rocky road to regulation. Nature Reports: Stem Cells. 23 September 2009 [cited 2014 February 13]; doi:10.1038/stemcells.2009.125, Available from: http://www.nature.com/stemcells/2009/0909/090923/ full/stemcells.2009.125.html

13. Barclay E. Stem-cell experts raise concerns about medical tourism. Lancet. 2009; 373(9667):883-4.

14. Stem cell tourism. California Institute for Regenerative 
Medicine [on line]. 2013 [cited 2014 February 12], Available from, http://www.cirm.ca.gov/our-progress/ concerns-about-stem-cell-tourism

15. Lindvall O, Hyun I. Medical innovation versus stem cell tourism. Science 2009; 324(5935):1664-5.

16. Clinicaltrials.gov. U.S. National Institutes of Health [on line]. 2013 [cited 2014 February 13], Available from: http://www.clinicaltrials.gov

17. Where can I get more information? In: Stem cell information. Bethesda, MD: Department of Health and Human Services, 2009 [cited 2014 February 13], Available at: http://stemcells.nih.gov/info/basics/ pages/basics7.aspx

18. FDA warns about stem cell claims. U.S. Food and Drug Administration [on line]. 6 January 2012 [cited 2014 February 13], Available from: http://www.fda.gov/ forconsumers/consumerupdates/ucm286155.htm

19. Ethical guidelines for publication in Asian Biomedicine.
Asian Biomedicine 2013; 7:911-2.

20. ISSCR patient handbook on stem cell therapies. International Society for Stem Cell Research [on line] 3 December 2008 [cited 2014 February 13], Available at: http://www.isscr.org/visitor-types/public/aboutstem-cell-treatments

21. Sivaraman MAF, Noor SNM. Ethics of embryonic stem cell research according to Buddhist, Hindu, Catholic, and Islamic religions: perspective from Malaysia. Asian Biomedicine 2014; 8:43-52.

22. Ai J, Azizi E, Shamsian A, Eslami A, Khoshzaban A, Ebrahimi-Barough S, Alizadeh A. BMP-2 can promote the osteogenic differentiation of human endometrial stem cells. Asian Biomedicine 2014; 8:21-9.

23. Hua S, Chung H, Sidhu K. Human therapeutic cloning, pitfalls and lacks luster because of rapid developments in induced pluripotent stem cell technology. Asian Biomedicine 2014; 8:5-10. 